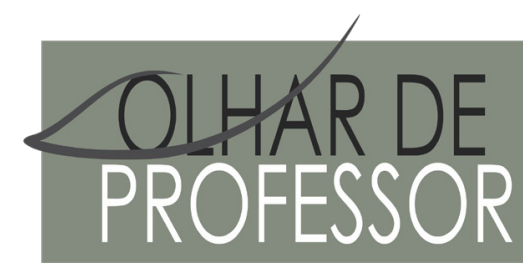

DOI: 10.5212/OLHARPROFR.v.23.2020.16385.209209230208.0904

\title{
SABERES DA DOCÊNCIA UNIVERSITÁRIA E CICLO GNOSIOLÓGICO EM PAULO FREIRE: TESSITURAS A PARTIR DA PÓS-GRADUAÇÃO EM EDUCAÇ̃̃o
}

\author{
KNOWLEDGE OF THE UNIVERSITY TEACHING AND GNOSIOLOGICAL CYCLE IN PAULO FREIRE: TESSITURES \\ FROM THE GRADUATE EDUCATION
}

\author{
CONOCIMIENTO DEL CICLO UNIVERSITARIO DE ENSEÑANZA Y GNOSIOLÓGICO EN PAULO FREIRE: \\ TESITURAS DE LA EDUCACIÓN GRADUADA
}

\author{
HAMILTON PERNINCK VIEIRA* \\ JACQUES THERRIEN**
}

\begin{abstract}
Resumo: Este artigo apresenta resultados de uma pesquisa de doutoramento entre 2016 e 2020 que objetiva compreender a partir da ontologia, da epistemologia e da práxis pedagógica a dialética das aproximações e/ou dos distanciamentos dos saberes da docência universitária em relação ao Ciclo Gnosiológico em Paulo Freire. Tratase de um estudo etnometodológico de abordagem qualitativa, a partir da bricolagem científica enquanto postura investigativa. A pesquisa bibliográfica, a análise documental, o questionário on-line, a entrevista com base em casos hipotéticos de ensino e a entrevista de explicitação foram as técnicas de coleta de dados vivenciadas com seis mestres e doutores egressos do Programa de Pós-Graduação em Educação da Universidade Estadual do Ceará (PPGE-UECE) entre 2004 e 2017. Os achados apontaram que o Ciclo do Gnosiológico freiriano contribui para pensar e impulsionar a constituição dos saberes da docência universitária a partir da do-discência, da pesquisa e do diálogo intersubjetivo.
\end{abstract}

Palavras-chave: Saberes da docência universitária. Ciclo Gnosiológico em Paulo Freire. Pós-graduação em Educação.

\begin{abstract}
This article presents results of a doctoral research between 2016 and 2020 that aims to understand from the ontology, epistemology and pedagogical praxis the dialectic of the approaches and / or distances of the knowledge of university teaching in relation to the Gnosiological Cycle in Paulo Freire. This is an ethnomethodological study with a qualitative approach, based on scientific bricolage as an investigative posture. Bibliographic research, document analysis, on-line questionnaire, interview based on hypothetical teaching cases and the explanation interview were the data collection techniques experienced with six masters and doctors graduated from the Graduate Program in Education at the State University of Ceará (PPGE-UECE) between 2004 and 2017. The findings pointed out that the Freirean Gnosiological Cycle contributes to thinking and promoting the constitution of university teaching knowledge based on do-discourse, research and intersubjective dialogue.
\end{abstract}

Keywords: Knowledge of university teaching. Gnosiological Cycle in Paulo Freire. Post-Graduation in Education.

Resumen: Este artículo presenta los resultados de una investigación doctoral entre 2016 y 2020 que tiene como objetivo comprender desde la ontología, epistemología y praxis pedagógica la dialéctica de los enfoques y / o

\footnotetext{
* Doutor em Educação pela Universidade Estadual do Ceará (UECE, Fortaleza, CE, Brasil). Professor da Secretaria Municipal de Educação (SME) em Fortaleza, CE, Brasil. E-mail: hpv_@hotmail.com.

${ }^{* *}$ Doutor em Educação pela Cornell University (CU, Ithacha, Nova York, USA), professor Titular (aposentado) da Universidade Federal do Ceará (UFC) e docente visitante do Programa de Pós-Graduação em Educação da Universidade Estadual do Ceará (PPGE-UECE) em Fortaleza, CE, Brasil. E-mail: jacques@ufc.br.
} 
distancias del conocimiento de la enseñanza universitaria en relación con el ciclo gnosiológico en Paulo Freire. Este es un estudio etnometodológico con un enfoque cualitativo, basado en el bricolaje científica como una postura de investigación. La investigación bibliográfica, el análisis de documentos, el cuestionario en línea, la entrevista basada en casos hipotéticos de enseñanza y la entrevista de explicación fueron las técnicas de recopilación de datos experimentadas con seis maestros y médicos graduados del Programa de Posgrado en Educación en la Universidad Estatal de Ceará (PPGE-UECE) entre 2004 y 2017. Los hallazgos señalaron que el Ciclo Gnosiológico freiriano contribuye a pensar y promover la constitución del conocimiento de la enseñanza universitaria basada en el discurso del discurso, la investigación y el diálogo intersubjetivo.

Palabras-clave: Conocimiento de la docencia universitaria. Ciclo Gnosiológico en Paulo Freire. Postgrado en Educación.

\section{INTRODUÇ̃̃o}

Esta pesquisa é resultado de estudo anterior de doutoramento no campo da formação de professores articulado à constituição dos saberes da docência universitária (VIEIRA, 2020) a partir da experiência de egressos do Programa de Pós-Graduação em Educação da Universidade Estadual do Ceará (PPGEUECE). Nesse sentido, a partir da metáfora da tecelagem adotada na pesquisa e mediante as aproximações com os fios que tecem o objeto de estudo, é preciso justificá-lo e problematizá-lo (GAMBOA, 2009), apresentando seu tríplice trançado.

No primeiro trançado, verifica-se que a Pós-Graduação Stricto Sensu (PGSS) e, como consequência, a Pós-Graduação Stricto Sensu em Educação (PGSSE) têm como missão maior a formação de pesquisadores especializados, e não de docentes. Geralmente, o mestre e o doutor formados nesses Programas dominam as competências teórico-metodológicas da pesquisa, mas esses profissionais, ao assumirem concurso na universidade, não serão admitidos como pesquisadores, mas como professores. Portanto, é possível perceber um processo de hierarquização da pesquisa e de secundarização da docência na universidade (FELDEN, 2013), em vez de pensar essas duas categorias como fundantes do egresso da PGSS em situação de ensino (FREIRE, 1996; DEMO, 2002; SEVERINO, 2009).

Relacionado a isso, o segundo trançado relaciona-se à legislação educacional resultante do discurso neoliberal ancorado no ideário da competência, que tem levado professores do ensino superior à busca de especializações, mestrados, doutorados e pós-doutorados sem o real sentido dessa empreitada formativa. Segundo dados do Instituto Nacional de Pesquisas Anísio Teixeira (INEP, 2017), havia 392.036 professores que atuavam nessas universidades públicas (179.542) e privadas (212.494). Nota-se, como resultado do neoliberalismo na educação, que a rede privada (54\%) absorvia 8\% a mais de docentes universitários em relação à rede pública de ensino superior (46\%).

Além disso, quanto à titulação, os dados (INEP, 2017) mostram que havia 10 docentes sem graduação, 4.613 graduados (1\%), 72.301 especialistas (19\%), 153.285 mestres (39\%) e 160.827 doutores (41\%). Logo, é possível perceber que se tem $2 \%$ a mais de doutores em relação ao número de mestres, mas estão quase equiparados. Grosso modo, a titulação não é garantia de que o professor universitário tenha conhecimentos e vivências pedagógicas que lhes possibilitem condições de mediar o processo de aprendizagem de modo que o conteúdo seja acessível à compreensão dos alunos. Portanto, saber não é saber ensinar.

Nessa direção, o terceiro trançado abordou o discurso do saber desarticulado do saber ensinar. Afirma-se que a docência universitária não está apenas pautada no saber fazer (competência), mas também que é preciso saber fazer bem (habilidades). Logo, a naturalização da docência como dom, uma mera extensão do mundo do trabalho no bojo da concepção da ciência moderna, e, por conseguinte, sua secundarização no contexto da vida acadêmica, abriu espaço para nossa indagação nesta pesquisa: Quais as aproximações e/ou os distanciamentos do Ciclo Gnosiológico em Paulo Freire com os saberes da docência universitária a partir de egressos do PPGE-UECE? Tal questão central conduziu ao objetivo geral de compreender a partir da ontologia, da epistemologia e da práxis pedagógica de alunos egressos do PPGE-UECE a dialética das aproximações e/ou dos distanciamentos dos saberes da docência universitária em relação ao Ciclo Gnosiológico em Paulo Freire. 
Sendo assim, compreende-se que há

[...] lacunas pedagógicas, de ordem filosófica, didático-pedagógica e ainda problemas de concepção de epistemologia e problemas metodológicos na sala de aula, a questão central é que os professores universitários, em geral, no Brasil como alhures, não tiveram o devido preparo pedagógico para a assunção de uma sala de aula (D’ÁVILA; VEIGA, 2012, p. 8).

Além disso, os estudos da Pedagogia tinham foco na criança, assim como já diziam os gregos. Identificada como campo de estudo tributário da Psicologia do desenvolvimento e da aprendizagem e da Antropologia Filosófica, a Pedagogia não era tida como uma Ciência que tinha seu território de investigação que dialogava com os diversos campos do saber acadêmico (FRANCO, 2003; SCHMIEDKOWARZIK, 1988). Portanto, a Pedagogia, ao chegar ao Ensino Superior, trouxe em seu bojo o aspecto meramente instrumental da docência.

Sendo assim, após essas discussões introdutórias, o projeto de redação desta investigação segue pela fundamentação teórica, metodologia, análise de dados, conclusões do estudo e referências.

\section{FUNDAMENTAÇ̃̃O TEÓRICA}

Nessa seção, discute-se o conceito e os modelos que teceram os fios constituintes da universidade no Brasil. Em seguida, trabalha-se a racionalidade que subsidia a teoria e a prática na docência universitária, justificando a nossa opção pela epistemologia freiriana no que se relaciona as três categorias teóricas que integram o ser docente na universidade, quais sejam: a ontologia, a epistemologia e a práxis pedagógica (THERRIEN, 2014).

A universidade é uma instituição que teve suas origens no século XII no contexto da escolástica medieval (TEIXEIRA, 1989 apud OLIVEN, 2002). Na compreensão de Pimenta e Anastasiou (2002), a universidade no Brasil se consituiu a partir de três modelos formativos: o jesuíta, o francês e o alemão; com base na literatura, pode-se mencionar também a influência do modelo americano. A universidade no Brasil, portanto, foi marcada por esses quatro modelos, e isso trouxe implicações sobre o modus operandi da docência universitária e sobre a constituição da PGSSE.

De um lado, o modelo jesuítico, na Colônia, lançou os fundamentos da "educação bancária”, assentada numa concepção didática da transmissão de conteúdos articulada à verticalização na relação professor e aluno, que evoca certa aura de poder em torno do primeiro no tocante ao segundo, conduzindo a perspectiva do conhecimento como acabado. De outro lado, a experiência francesa, a partir do Império, costurou os fios burocratizantes e elitistas que ainda são marcas da graduação, sobretudo da Pós-Graduação no Brasil (PGB). Além do mais, o fenômeno da departamentalização oriunda das faculdades isoladas encontrou sistematização na Lei n 5.540/1968, que rege sobre a Reforma Universitária (BRASIL, 1968).

Em contraponto a essas duas influências, o modelo alemão no contexto da República Velha apontou para a necessidade da pesquisa com base na criatividade, na autonomia e na cooperação entre os docentes, porém trazendo a cisão entre o ensino e a pesquisa: o primeiro ficou a cargo da graduação; e o segundo, da pós-graduação (PIMENTA; ANASTASIOU, 2002). Por fim, o modelo americano contribuiu para a departamentalização da universidade — já apontada na influência francesa —, para a criação do regime de cátedras e sua abertura para o capital e, por consequência, para a privatização do ensino superior no Brasil entre os anos 1960 e 1970.

Após essa discussão sobre os modelos de universidade, considera-se necessária uma palavra acerca das decorrentes racionalidades que permitem a tessitura dos fios da docência universitária e que reforçam a cisão ou a articulação entre o saber e o saber ensinar. Nesse sentido, entende-se a racionalidade, segundo Boufleuer (2001, p. 11), “como conjunto de pressupostos que estruturam e condicionam, o pensamento de toda uma época."

Diante disso, entende-se que a racionalidade dos sujeitos no mundo é constituída dos pressupostos, explícitos e/ou implícitos, que configuram um paradigma filosófico (sentido stricto) e que estruturam e condicionam o pensamento de uma época (sentido lato). Em outras palavras, é o modus vivendi e o 
modus operandi do sujeito, que pode ora se voltar para uma racionalidade mais vertical e fechada, ora para uma racionalidade horizontal e aberta.

A partir dessas constatações teóricas, assevera-se que a ciência e a docência universitária foram marcadas fundamentalmente pela racionalidade dos pensamentos de René Descartes (1596-1650), Isaac Newton (1643-1727) e Augusto Comte (1798-1857). Dessa forma, “[...] nos últimos 300 anos, a ciência se consolidou apoiada nesse paradigma newtoniano-cartesiano, definido como tudo que pode ser observado de forma objetiva, neutra, constante e positiva em suas manifestações.” (REIS, 2011, p. 57).

Posto isso, no "esquartejamento epistemológico" (NUNES, 2002) da modernidade, as cisões saber-fazer, razão-sentimento, ciência-fé, sujeito e objeto foram postas como os fundamentos filosóficos do método científico, como pensar a docência e o fenômeno educativo em sua complexidade e multirreferencialidade (BARBOSA, 1998), ou na dimensão cultural e crítica da dialética disciplinaridade/interdisciplinaridade/transdisciplinaridade? (KINCHELOE; MCLAREN, 2006). Ensinar e aprender, portanto, envolvem o pensamento, os sentimentos e as ações humanas, tendo em vista um campo de totalidade que atravessa professores e alunos como sujeitos integrais no processo de construção do conhecimento.

Nessa direção, pensar a docência universitária é tecer relações entre a realidade e a mediação dos saberes culturalmente acumulados pela humanidade. A função da universidade é construir processos significativos de aprendizagem que considerem o contexto existencial, econômico, social, político e pedagógico como ponto de partida, tendo a humanização como ponto de chegada e o conhecimento como mediação do processo (BRAGA, 2012; FREIRE, 1996; MENDONÇA, 2008).

Diante dessas proposições, faz-se a opção teórico-metodológica pela epistemologia freiriana na costura dos fios que tecem a formação na PGSSE e defende-se que, para além de um método de alfabetização, a proposta de Paulo Freire é uma possibilidade de superação dos “nós” atados na história da ciência e da Pedagogia, sobretudo pelo Positivismo que levou a cabo o projeto filosófico cartesiano-newtoniano, que não permitiu os reais alinhavamentos entre teoria e prática, razão e emoção, sujeito e objeto, ciência e fé, racionalidade técnica e racionalidade prática, docência e pesquisa, dentre outras (SILVA, 2013). Em suma, para além de um método de alfabetização, Freire propõe no século XX uma epistemologia praxiológica (FIGUEIREDO, 2003) aberta, que pensa o global a partir do local (SANTOS, 2008), propondo a injunção daquilo que foi disjuntivo no contexto da Modernidade.

Diante disso, para além de repeti-lo, objetiva-se reinventar sua epistemologia praxiológica, compreendendo que "[...] talvez o importante não seja o que Freire disse, ou o porquê disse, ou o como disse. Mas o mais importante talvez seja o que Freire pode dar a dizer.” (CARDARELLO, 2005, p. 20). Logo, Freire não foi superado porque ele precisa ser recriado em quaisquer contextos de educação formal e/ou não formal, por conta da abertura de sua epistemologia — no caso desta pesquisa, o campo da docência universitária (VIEIRA, 2015).

Entende-se nesta pesquisa, como base no arranjo teórico-metodológico, que os saberes da docência universitária se constituem através da tríade ontologia, epistemologia e metodologia (THERRIEN, 2014), focalizando a centralidade do Ciclo Gnosiológico, que se articula a partir das subcategorias Do-discência ${ }^{1}$ e Pesquisa, que se materializam através do diálogo intersubjetivo. Trabalhou-se na pesquisa através de três conceitos-chave: ontologia na perspectiva do Ser Mais, epistemologia da PGSSE e metodologia da práxis pedagógica.

Do ponto de vista da ontologia, compreende-se que a docência universitária é um aprendizado que não se dá apenas na PGSS, mas ao longo da vida, através de imagens construídas enquanto o futuro professor vai sendo aluno. Destaca-se que, na ontologia freiriana, o inacabamento está ligado à inconclusão

\footnotetext{
${ }^{1}$ Como Freire busca recompor dialeticamente em sua epistemologia o que se percebe dicotomizado na Ciência moderna (ciência e senso comum, natureza e cultura, teoria e prática, docência e pesquisa, razão e emoção, todo e parte, subjetividade e objetividade etc.), muitas vezes não encontra palavras para nomear os seus conceitos. Por isso cria neologismos, dentre os quais o termo Do-discência. Dessa forma, ao elaborar o processo de conhecimento no Ciclo Gnosiológico, a Do-discência postula a realidade de que o ensinar e o aprender estão imbricados numa relação dialógica e dialética em que um só existe na relação com o outro. Quem ensina, aprende ao ensinar; e quem aprende, ensina ao aprender. A Do-discência trabalha com o que a ciência já sabe. Em contraponto, a pesquisa busca conhecer o que ainda se ignora. Freirianamente falando, a partir da Do-discência, na relação educador-educando, pode-se dizer que houve ensino se realmente houve aprendizagem do conhecimento culturalmente acumulado pela humanidade, em um determinado contexto situado da ação didática.
} 
e à imperfeição dos humanos. Nesse sentido, o inacabamento e a consciência da inconclusão perfazem a matriz de sua "educabilidade" humana (FREIRE, 2000) na esteira da imperfeição ao longo da vida.

Com base nisso, em Freire compreende-se que “[...] todos os seres são incompletos, porque necessitam uns dos outros; são inconclusos, porque estão em evolução; e são inacabados, porque são imperfeitos.” (ROMÃO, 2010, p. 292). A incompletude do homem o conduz à horizontalidade; a inconclusão ao movimento em prol da evolução e o inacabamento instituem a sua condição de imperfeição (SILVA, 2013).

Sobre a epistemologia da PGSSE, mediante as proposições de Freire, concebe-se que a Pedagogia é uma teoria do conhecimento posta em prática, fundamentada enquanto ato político (o poder), ato estético (o belo) e ato de conhecimento (o saber). Nesse sentido, não há como dicotomizar na ação educativa o político, o estético e o epistemológico. Essa teoria "[...] é naturalmente política, tem que ver com a pureza, jamais com o puritanismo e é em si uma experiência de boniteza.” (FREIRE, 2000, p. 89).

A politicidade do ato educativo faz dele um movimento de busca pela estética, de forma que a não aceitação da realidade da feiura do mundo como está mobiliza os sujeitos aprendentes para a boniteza e o sonho a partir do que entendem que ele deva ser. Em síntese, "além de um ato de conhecimento, a educação é também um ato político. É por isso que não há pedagogia neutra.” (FREIRE; SHOR, 1986, p. 25).

A epistemologia da PGSS, por conseguinte, enquanto currículo sistematizado da Pedagogia, possibilita ao professor universitário a compreensão das teorias que fundamentam a docência universitária na direção da formação humanística e científica de mestres e doutores. Segundo a nossa óptica, os saberes da docência universitária estão relacionados à Pedagogia Freiriana que propõe o Ciclo Gnosiológico, que compreende a do-discência e a pesquisa, elementos esses que se materializam no contexto da dialogicidade.

Essa circularidade dialógica viabiliza ao pós-graduando, em formação institucionalizada em nível de mestrado e/ou doutorado, a constituição dos saberes da docência universitária. Dessa maneira, a partir do que se discutiu até aqui em relação ao Ciclo Gnosiológico, que se fundamenta na do-discência e na pesquisa, compreende-se que a dialógica freiriana como paradigma científico e, por conseguinte, civilizatório, articula-se aos conceitos de pensar certo, curiosidade epistemológica, criatividade e criticidade (FREIRE, 1981b, 1983, 1993, 1996, 2001; FIGUEIREDO, 2003; MARTINS; ALVIN, 2012; MAURENTE, 2015; WEYH, 2008).

Por fim, sobre a metodologia da práxis pedagógica, afirma-se que, se a docência não é um ofício destituído de saberes (GAUTHIER et al., 1998), é preciso reconhecer que a metodologia da aula se materializa na Didática, enquanto ação pedagógica situada no campo da docência universitária. Os saberes pedagógicos (entre)tecidos a partir do campo da educação permitem a vivência da práxis pedagógica na dimensão do currículo. Nesse momento é que a epistemologia constituída orienta ao professor na universidade para articular o saber ao saber ensinar, em contexto situado entre a teoria e a prática.

Apesar disso, no campo da docência universitária, por ser fundamentada na racionalidade técnica, que focaliza os esforços no saber em detrimento do saber ensinar, a teoria está separada da prática. As fissuras postas pelo reducionismo da ciência moderna aumentam o fosso e hierarquizam a relação entre o saber e o saber ensinar na universidade, priorizam a pesquisa e secundarizam a docência, distanciando-se da práxis pedagógica.

Nesse sentido, "separada da prática, a teoria é puro verbalismo inoperante; desvinculada da teoria, a prática é ativismo cego. Por isso mesmo é que não há práxis autêntica fora da unidade dialética ação reflexão, prática - teoria.” (FREIRE, 1981b, p. 135). Em síntese, “a condição de tensão aberta da relação significa evitar a imposição de uma polarização.” (VOLOSKI, 2013, p. 44).

Por essas reflexões sobre a tensão aberta entre a teoria e a prática, que considera tanto a unidade quanto a singularidade dessa relação, a Didática deixa de ser somente a teoria do ensino e passa a ser a teoria da formação permanente de professores (FRANCO, 2010; FREIRE, 1993) na docência universitária, com vistas à transformação dos saberes da Pedagogia em saberes pedagógicos (PIMENTA, 2008).

Freirianamente colocando isso, "a formação permanente das educadoras, que implica a reflexão crítica sobre a prática, se funda exatamente nesta dialeticidade entre prática e teoria.” (FREIRE, 1993, p. 112). Desse modo, a consciência da/na prática, que permite a reflexão nela/sobre, exige e gesta os fios da ciência de si mesma por meio da técnica que contribui para seus enviezamentos na formação e na docência universitária. Portanto, "a prática de que temos consciência exige e gesta a ciência dela. 
Daí que não possamos esquecer as relações entre a produção, a técnica indispensável a ela e a ciência.” (FREIRE, 1993, p. 102, grifo do autor).

\section{METODOLOGIA}

Este estudo é de natureza qualitativa e assenta-se no paradigma da teoria crítica em aproximações com a etnometodologia. A postura investigativa assumida é a bricolagem científica. A pesquisa bibliográfica, a análise documental, o questionário on-line aberto semiestruturado, a entrevista com base em casos hipotéticos de ensino (E1) e a entrevista de explicitação (E2) foram as técnicas de coleta de dados vivenciadas com seis mestres e doutores egressos do PPGE-UECE entre 2004 e 2017.

Com base na abordagem qualitativa, assumiu-se a bricolagem científica como postura investigativa com base na teoria crítica (FREIRE, 1981a, 1996; SAVIANI, 2008). Essa escolha foi feita baseada no reconhecimento das contribuições do pensamento newtoniano-cartesiano assentado do rigor da lógica e da objetividade da ciência, mas ao mesmo tempo em que se destacam as suas limitações impostas pela linearidade e pela fragmentação do conhecimento, na medida em que nega a subjetividade, a politicidade e a historicidade próprias das pesquisas em Ciências Humanas e Sociais, nas quais a Educação está assentada. (KINCHELOE; BERRY, 2007; NEIRA; LIPPI, 2012; RODRIGUES et al., 2016).

Em suma, a partir da concepção da teoria crítica de que a ciência busca a transformação da realidade e não a manutenção do status quo, considera-se a "[...] a ruptura epistemológica em direção a uma aproximação do fazer educativo de forma complexa e não de maneira compartimentada, isolada do social, dos processos políticos, econômicos, históricos e culturais [...].” (BARBOSA; BARBOSA, 2008, p. 247).

Posto isso, a inserção no campo empírico se deu através de aproximações com o tear da etnometodologia (GARFINKEL, 2006). Segundo Cunha, Farias e Sales (2011), esse modo de apreender a realidade do objeto teve origem com o sociólogo americano Harold Garfinkel, que construiu seu pensamento com base em Talcott Parsons (Teoria da Ação/Teoria Psicanalítica de Freud), na fenomenologia de Alfred Schutz e Eduard Hurssel e no internacionalismo simbólico da Escola de Chicago. Nesse sentido, a etnometodologia substitui o estudo do fenômeno social a partir das concepções durkheimianas de relações determinísticas de causa e efeito pelas relações de sentido produzido pelos atores em interação em situação formativa (COULON, 1995; SILVEIRA; ARAÚJO; FARIAS, 2011).

O campo empírico desta pesquisa é o PPGE-UECE, tendo em vista a proposta da relação entre os saberes da docência universitária e o Ciclo Gnosiológico em Paulo Freire. Em relação às regiões brasileiras, verificou-se que, dos 4.291 programas de PGSS brasileiros, 237 estão no Norte (6\%), 863 no Nordeste (20\%), 350 no Centro-Oeste (8\%), 926 no Sul (21\%) e 1.915 no Sudeste (45\%) (GEOCAPES, 2019). Dos 863 Programas de Pós-graduação nordestinos, o Ceará destaca-se em $3^{\circ}$ lugar, com 125 Programas (14\%), perdendo apenas para Pernambuco, em segundo lugar, com 161 Programas (19\%), e para a Bahia, em primeiro lugar, com 180 Programas (21\%). Nesse contexto geral da PGSS, no Brasil existiam 176 Programas na área da educação (4\%), dos quais 52 são de mestrado, 46 de mestrado profissional e 78 de mestrado/doutorado.

Diante disso, no Nordeste, identificou-se 33 PPGE, dos quais 4 estão no Ceará: 1 mestrado profissional na área de Educação na Universidade Regional do Cariri (URCA), 2 Programas completos de educação (mestrado e doutorado acadêmicos), sendo 1 na Universidade Federal do Ceará (UFC) (com área de concentração em educação brasileira) e 1 na UECE (com área de concentração em formação de professores).

Os sujeitos da pesquisa são mestres e doutores egressos do PPGE-UECE de 2013 a 2017. Por meio da observação dos dados disponíveis na aba corpo discente no site do Programa (http://www.uece.br/ ppge/), foi possível verificar que, nesse recorte temporal, havia 360 estudantes, sendo 262 alunas (73\%) e 98 alunos (27\%). Do Curso de Mestrado Acadêmico em Educação (CMAE), existem 280 egressos, dos quais 72 são alunos (26\%) e 208 são alunas (74\%). Do Curso de Doutorado Acadêmico em Educação (CDAE), 80 estudantes concluíram o curso, dos quais 54 são alunas (68\%) e 26 são alunos (32\%). Em 
suma, do universo desses 360 pós-graduados que passaram pelo PPGE-UECE de 2004 a 2017 é que se retirou a amostra dos sujeitos desta pesquisa.

Posto isso, com base na intencionalidade que nos levou a recortar o objeto e amostra da pesquisa, os seguintes critérios de seleção nortearam as nossas escolhas dos sujeitos que contribuíram empiricamente para a constituição da pesquisa: a) os sujeitos da pesquisa tinham que ser egressos que haviam passado pela formação stricto sensu do mestrado e do doutorado no PPGE-UECE de 2004 (conclusão da primeira turma do CMAE) a 2017 (conclusão da primeira turma do CDAE); b) professores que tinham pelo menos quatro anos de carreira na docência em universidades públicas ou privadas.

Justifica-se esse recorte temporal com base no ciclo da vida profissional de Hubermann (2013). Na concepção desse autor, a vida profissional se desenvolve através da entrada e tateamento (1-3 anos), estabilização, consolidação de um repertório pedagógico (4-6 anos), diversificação, "ativismo" e "questionamento" (7-25 anos), serenidade, distanciamento afetivo e conservantismo (25-35 anos) e desinvestimento (sereno ou amargo).

A partir dessas premissas, foi enviado o questionário on-line aberto semiestruturado para 41 sujeitos, doutores ou doutorandos das turmas de 2013, 2014 e 2015, pois se intencionou saber quantos tinham feito mestrado no PPGE-UECE e quantos na época não eram mais professores iniciantes na docência universitária. Da turma de 2013, 9 responderam o questionário (75\%); da turma de 2014, dos 15 alunos, 8 responderam o questionário (53\%); e por fim, da turma de 2015, dos 14 alunos, 10 responderam (67\%). Assim, a pesquisa trabalhou com 27 respostas, ou seja, $66 \%$ do total de alunos das três turmas de doutorado.

Sendo assim, em relação aos procedimentos de coleta de dados, com base em Lakatos e Marconi (2003), o trabalho de campo foi vivenciado em três fases. Na Fase 1, a pesquisa bibliográfica como fonte secundária de literatura especializada (LAKATOS; MARCONI, 2003; GIL, 2002) ajudou a entender o contexto histórico do surgimento da PGSS e suas particularidades na área da educação e do PPGE-UECE, desde suas origens, atreladas ao estudo documental (SÁ-SILVA; ALMEIDA; GUINDANI, 2009).

Com base na concepção do documento como síntese particular e provisória das relações de poder de uma época no contexto mais amplo do tecido social (FARIAS; BEZERRA, 2010), foi feita a leitura crítica do Projeto do Curso de Mestrado em Educação (PCMAE) (UECE, 2003) e da Proposta Institucional do Curso de Doutorado em Educação (PICDAE) (UECE, 2011), articulados ao Estatuto e às normas da PGSS na UECE, aos editais de seleção de 2003 a 2017, às portarias e resoluções internas relativas à temática e às normas para credenciamento de professores do Programa no contexto desse recorte temporal.

Adentrando no campo empírico, quanto aos cuidados éticos com os sujeitos envolvidos na pesquisa, foram evidenciados os princípios da Resolução CNS 510/2016, que tratam da ética nas pesquisas em Ciências Humanas e Sociais, através da assinatura do Termo de Consentimento Livre e Esclarecido (TCLE) antes das entre-vistas (MACEDO, 2006). Os sujeitos foram informados sobre a natureza, os objetivos, a possibilidade de desistência a qualquer momento da pesquisa, a ausência de riscos e os benefícios da investigação para a área da Educação, especificamente para a formação e a docência de professores universitários no contexto da PGSS.

Na Fase 2, antes do envio do questionário on-line (FARIAS et al., 2015; FARIAS; SILVA; CAVALCANTE, 2015), foi feito o pré-teste com doutorandos da turma de 2016 do PPGE-UECE (02 a 09 de março de 2019), para verificar a clareza das questões desse instrumento a ser usado para que se chegasse à amostra da pesquisa (GIL, 2002). O primeiro período de envio do questionário foi de $20 \mathrm{a}$ 31 de março de 2018. Entretanto, por conta de alguns e-mails não terem chegado, fez-se contato com sujeitos-chave das turmas de 2013, 2014 e 2015 pelo WhatsApp, na busca de respostas ao questionário on-line, alargando o período de envio de 06 a 21 de abril do corrente ano.

Das respostas que se obteve dos questionários on-line, faltaram informações sobre 14 alunos dos 41 alvos da coleta de dados: 3 alunos da turma de 2013, 7 alunos da turma de 2014 e 4 alunos da turma de 2015. Por isso, em 16 de abril de 2018, foi feita uma busca no Currículo Lattes dos 41 sujeitos para verificar a possibilidade de ainda encontrar doutorandos que foram mestrandos no PPGE-UECE. Com base nos dados do Currículo Lattes desses 14 sujeitos, articulados às informações do questionário on-line, conseguiu-se estabelecer com clareza a amostra da pesquisa. 
Desses 41 sujeitos, 19 (43\%) pós-graduandos passaram pelo mestrado e pelo doutorado no Programa. Da turma de 2013, identificou-se 12 alunas, das quais 4 fizeram mestrado e doutorado no PPGE-UECE e estavam atuantes na docência universitária no contexto do Ceará. Contudo, apenas 2 tinham mais de 4 anos de experiência na educação básica e na educação superior, são elas: Pavão Misterioso e Chico Anysio. Da turma de 2014, de um total de 15 alunos, dos quais 8 fizeram mestrado e doutorado no PPGE-UECE e estavam atuantes na docência universitária no contexto do Ceará, foram selecionados os 2 que têm mais tempo de experiência na educação básica e superior: Jáder de Carvalho e Jovita Feitosa.

Por fim, na turma de 2015, encontrou-se a realidade de 14 alunos, dos quais 7 fizeram mestrado e doutorado no PPGE e estavam atuantes na docência universitária no contexto do Ceará, selecionando apenas 2 que tinham maior tempo na docência universitária: Rachel de Queiroz e Iracema. Em síntese, foi vivenciado com 6 sujeitos o trabalho intersubjetivo da coleta e da análise de dados.

No processo de coleta de dados da pesquisa, os dados empíricos oriundos das E1 e E2 foram tratados em três momentos distintos e complementares entre si: a transcrição, a textualização e a validação dos dados. Na transcrição, a gravação em áudio foi transformada em texto de fala bruta. A coloquialidade do discurso oral dos entre-vistados foi respeitada tal e qual, considerando a todo momento as pausas, as interrupções de pensamento, as incompreensões das frases por conta da espontaneidade da fala, as interjeições, as emoções e os vícios de linguagem (uso do "é”, "né” e contrações de palavras) dos sujeitos no processo de elaboração do pensamento para responder nossas perguntas.

Diante disso, decidiu-se que o material empírico a ser utilizado na pesquisa precisava estar de acordo com a norma culta da Língua Portuguesa, sem, contudo, retirar do texto a espontaneidade e a coloquialidade da oralidade, por isso a prática da textualização. Para tanto, foi feita a limpeza no texto dos "és", dos "nés", das palavras repetidas e buscou-se, ainda, em momentos de interrupções do pensamento dos entrevistados, refazer a tessitura do material empírico bruto em relação à coesão e à coerência das falas, mantendo sempre a lógica da intensão original, o regionalismo, palavras, verbos e expressões contraídas usadas no cotidiano que não afetam a compreensão do pensamento, mas que contribuem para deixar as marcas da singularidade e da pessoalidade de cada participante da pesquisa.

Por fim, levando em consideração que a entrevista é um processo intersubjetivo de olhar a realidade na interface "entre-vistas", conforme Macedo (2006), devolveu-se o material textualizado das entre-vistas por e-mail aos sujeitos, para a validação dos dados. Por meio de uma legenda de cores, foram apontadas no texto da fala bruta as repetições, as sugestões de supressão ([...]) e acréscimos para deixar o texto mais fluido. Esse procedimento foi feito para garantir que a coesão e a coerência percebidas nas falas das entre-vistas refletissem tal e qual o que cada entre-vistado pensou quando respondeu as E1 e E2.

Em decorrência desse movimento de leitura do questionário on-line e das E1 e E2 na Fase 2, procedeu-se à análise categorial dos dados empíricos na Fase 3 (GHEDIN; FRANCO, 2011; OLIVEIRA, 2010). Sendo assim, compreendeu-se que as categorias de análise emergem das teorias e orientam a opção metodológica. Além do mais, ajudam na organização do esquema de registro e da formulação conceitual que reconduz a base filosófica. Esse caminho de análise da empiria permitiu a elaboração de um esquema dialético de registros na busca da (re)elaboração das categorias teóricas postuladas no referencial teórico, que emerge da Pedagogia Freiriana focalizada no Ciclo Gnosiológico freiriano e de suas relações com os saberes da docência universitária.

Afirma-se, portanto, que "as categorizações são maneiras pelas quais os atores descrevem e 'estruturam' o mundo e, para fazer isso, criam categorias ou 'tipos'” (LAPASSADE, 2005, p. 46). Tendo em vista perceber as descrições e as estruturas de mundo, trabalha-se na análise de dados a partir das relações entre as categorias teóricas, as categorias empíricas e as unidades de análise.

À luz das categorias teóricas, as categorias empíricas são concebidas como construtos que emanaram do material empírico oriundo dos questionários e das duas entrevistas. Elas podem se aproximar e/ou se distanciar das categorias teóricas, e é nesse emaranhado que os fios da teoria são ressignificados. São elas: saberes ontológicos do-discentes, saberes da racionalidade epistêmico-dialógica e saberes da práxis pedagógica. Por fim, as unidades de análise foram palavras-chave que ajudaram a pensar sobre as categorias empíricas na busca de novos entretecimentos das categorias teóricas. 


\section{ANÁLISE DE DADOS}

Nesta seção, apresenta-se um recorte da análise de dados da Tese, mediante uma primeira discussão do escopo mais amplo da proposta de criação do CMAE, em 2003, da proposta de criação do CDAE, em 2011, e de editais de seleção que foram constituindo historicamente PPGE-UECE como Programa completo. Num segundo momento, procurou-se tecer os fios que permitiram os alinhavamentos entre esses dois documentos e os dados empíricos oriundos do questionário on-line (Q), e das entrevistas (E1 e E2).

Com base na leitura da documentação, identifica-se dois períodos distintos de constituição das linhas, núcleos ou eixos de pesquisa: (1) De 2003 a 2011, quando havia só o CMAE; (2) De 2012 a 2017, quando PPGE se tornou um Programa completo, com mestrado e doutorado. No primeiro período (2003 a 2011), verifica-se a primeira vertente dos eixos de pesquisa voltados para a Didática e para a Política Educacional, atreladas à formação de professores como área de concentração. Assim, o mestrado visou "formar profissionais da educação capazes de compreender a prática docente em estreita vinculação com a totalidade social, por meio da articulação entre ensino e pesquisa, tornando-se como eixos principais a didática e a política educacional.” (UECE, 2003, p. 26).

Segundo a Proposta do Programa, não há como pensar a formação de professores sem o entendimento dos fios da prática docente e sem os enviezamentos da totalidade social, que permitem as tessituras, cores e contrastes na relação entre o ensino e a pesquisa (articulação que busca a superação das dicotomias ensino-pesquisa e graduação-pós-graduação) no campo da Didática (ensinar e aprender) e da política educacional (contexto econômico, cultural e social).

No segundo período (2012 a 2017), nota-se na instituição do PPGE enquanto Programa completo, o segundo outro eixo que materializou a área de concentração por meio da ênfase em estudos que trabalhem a formação inicial e continuada. A formação inicial e continuada (UECE, 2016, p. 2) agora era o prolongamento e o aprofundamento das discussões e pesquisas que, desde a origem do Programa, estavam focalizadas na Didática e na Política Educacional.

Esse novo eixo trouxe costuras com base em três grandes fios que se aproximam das categorias de análise desta pesquisa: o desenvolvimento profissional docente (saberes da racionalidade epistêmico-dialógica), a identidade docente (saberes ontológicos do-discentes) e a valorização da docência como atividade intelectual, crítica e reflexiva (práxis pedagógica) (THERRIEN, 2014). Em suma, com base nessas proposições legais, a docência universitária no PPGE-UECE é compreendida como atividade intelectual, crítica e reflexiva (HEERDT, 2014; PIMENTA, 2008; THERRIEN; LOIOLA, 2001; BERNARDINO JÚNIOR, 2011).

Os sujeitos da empiria foram identificados na pesquisa por alcunhas de personalidades cearenses que eles mesmos escolheram, quais sejam: Pavão Misterioso e Chico Anysio (turma de 2013); Jáder de Carvalho e Jovita Feitosa (turma de 2014); Rachel de Queiroz e Iracema (turma de 2015). Com base nos Q, em relação ao perfil dos sujeitos da amostra, a curva de idade é de 38 a 63 anos, o que corrobora os dados do recente estudo Doutores do Brasil, do Centro de Gestão e Estudos Estratégicos (2016, p. 94-95), ao afirmar que a idade média da titulação de doutores no Brasil caiu de 39,4 para 37,5 anos entre 1996 e 2014.

Em relação à formação, o retrato dos seis sujeitos que constituem a amostra deste estudo é predominantemente de pedagogos no tocante à formação inicial. Dois professores são exclusivamente pedagogos (Chico Anysio e Jovita Feitosa); três têm dupla formação inicial, das quais uma delas é a Pedagogia (Pavão Misterioso, Jáder de Carvalho e Rachel de Queiroz). Por fim, uma é historiadora que se fez docente universitária ao longo da formação continuada na área de Educação (Iracema).

Em relação à pesquisa empírica, os saberes ontológicos do-discentes correspondem à compreensão do fenômeno da educação como possibilidade do estabelecimento de relações de aprendizagem no bojo do processo amplo da cultura. Sendo a educação elemento dialeticamente influenciador e influenciado pela sociedade, no processo da constituição ontológica dos sujeitos no mundo, ela estabelece os fios de fundamentação política para a vida, baseada em processo de incorporação do contexto sociocultural. Nesse sentido, os sujeitos assim se posicionam: 
Acho que educação é algo que acontece em todos os espaços, não é restrito, obviamente, ao ambiente acadêmico nem escolar [...]. Eu acho que ela faz parte [...] do próprio processo de hominização. Quer dizer: o homem se torna homem através do processo educativo, que tá inserido no processo mais amplo da cultura, que é o grande diferencial [...] do ser humano (JÁDER DE CARVALHO - E2).

Educação é um processo humano, que faz parte das relações humanas e que está relacionado com o desenvolvimento da cultura, da relação entre os sujeitos e que tanto a educação influencia o desenvolvimento da sociedade como é influenciada por ela, pela sociedade (CHICO ANYSIO - E2).

A educação [...] é a fundamentação para a vida. Aquilo que vai permear toda a vida do estudante. Ela se inicia na família e é mediada pela escola. Então a educação escolar é só um tipo de educação, porque a educação no sentido mais amplo é aquilo que você vai incorporando os aspectos da cultura, os aspectos sociais, os aspectos políticos e ideológicos, de acordo com o contexto em que você vive (JOVITA FEITOSA - E2).

O entendimento da do-discência molhada de vida permitiu situar o diálogo enquanto necessidade humana ontológica de comunicação intersubjetiva, que assume contornos epistêmicos e, portanto, político-pedagógicos na do-discência e na pesquisa quando é eivado de intencionalidade do professor que pensa dialética e dialogicamente o sujeito cognoscente diante do objeto cognoscível.

Nesse sentido, no processo de constituição ontológica dos sujeitos no mundo, a perspectiva da educação crítico-problematizadora em Freire se coloca no horizonte da humanização e do diálogo no horizonte do Ser Mais, como espaço de construção com o Outro no bojo da corporeidade. Nesse primeiro momento, o diálogo não aparece como racionalidade epistêmica, mas como atitude humana de abertura intersubjetiva do eu para o Outro. Constata-se isso a partir da fala de um sujeito que afirmou:

Pra mim, o diálogo — tenho muito a perspectiva do Freire, quando defende o diálogo enquanto um espaço que você constrói com o outro. Eu acho muito bonito quando ele coloca que o diálogo não se faz sozinho, se faz com o outro. Então, acho que isso é importantíssimo, porque na medida em que você faz isso com o outro, o outro também se sente gente - parte do processo em que ele está vivendo. E isso leva à humanização (PAVÃO MISTERIOSO - E2).

O diálogo se coloca como espaço intersubjetivo que possibilita a humanização dos sujeitos na busca pelo Ser Mais coletivo (BRAGA, 2012; FREIRE, 2001; SILVA, 2013; FERREIRA, 2013). É um exercício de aprender a dizer eu na relação de partilha com o Outro. Esse movimento de sair de si e se encontrar com e no Outro permite o sentir-se "gente". Tal processo intersubjetivo de (re)conhecimento permite a voz e a vez de todos os sujeitos em comunhão.

Nesse sentido, esse sujeito da pesquisa constatou: "então, acho que isso traz esse processo de humanização. De sentir-me em um espaço onde todo mundo tem vez e voz, e todo mundo tem algo a contribuir com o que tá sendo discutido" (PAVÃO MISTERIOSO - E2). Segundo Pavão Misterioso, o diálogo é o espaço de construção do Eu com o Outro. Nessa construção, é fundamental que haja abertura para a voz e a vez que permitem a humanização através da escuta, da atenção e do valor do Outro.

O diálogo intersubjetivo permite a humanização porque dá voz e vez coletivas, pois se fundamenta na ideia de que todos têm algo a contribuir nas relações entre os sujeitos aprendentes (LOSSO, 2010; FREIRE, 1983). Diante disso, faz sentido pensar na corporeidade do diálogo, pois, "[...] para essa escuta sensível, preciso estar de corpo inteiro atento, disponível e não apenas a audição.” (PAVÃO MISTERIOSO - E2). O diálogo que se fundamenta na escuta sensível precisa ser corpóreo e não apenas abrir-se para o ouvir auricular.

O trançado de fios na urdidura estabelecida pelo Ciclo Gnosiológico e suas relações com os saberes da racionalidade epistêmico dialógica ajudam a pensar mundo afora na estrada que vai nos conduzir a outro lugar e chegar para ouvir. Sendo assim, defende-se conceitualmente, a partir da análise empírica, que o diálogo como necessidade humana ontológica de comunicação intersubjetiva assume contornos epistêmicos, e, por conseguinte, político-pedagógicos na do-discência e na pesquisa quando é eivado de intencionalidade do professor que pensa dialética e dialogicamente o sujeito cognoscente diante do objeto cognoscível. 
O diálogo, portanto, configura-se como racionalidade epistêmico-dialógica aberta, horizontal e problematizadora. Essa utopia epistemológica é não lugar possível que ajuda a pensar que os saberes ontológicos do-discentes são pedagogicamente fundamentos nos saberes da racionalidade epistêmico dialógica da PGSS, possibilitando, assim, a (re)elaboração dos saberes da práxis pedagógica. Nesse sentido, os sujeitos ponderam:

Então, quando a gente se coloca diante disso, nessa perspectiva de que você tá em constante aprendizado e adota uma postura de humildade, dizendo para eles que, se tiver alguma coisa que eles perguntem e que eu não sei, eu vou pesquisar junto com eles, a gente vai buscar juntos, você se coloca efetivamente nessa condição da responsabilidade de ter mais leitura e de trazer coisas importantes para favorecer, porque você é docente, você precisa ter isso. Mas o fato de você ter um doutorado não quer dizer que a gente é o dono do saber, o bambambãa, porque isso não existe, no mundo atual principalmente (JOVITA FEITOSA - E1).

Eu acho que, dentro de uma proposta, o diálogo — lá vou eu citar o Paulo Freire [risos] —é uma proposta que é, do meu ponto de vista, é a base pra você desenvolver o seu conhecimento. E você, pra desenvolver esse conhecimento também, a gente precisa problematizar. A gente precisa conhecer o contexto, questionar sobre e fazer problematizações. E a partir dessa problematização é que a gente vai conseguindo refletir sobre, pra avançar um pouco no conhecimento. E só é possível, pra mim, só é possível a partir do diálogo [...]. Você discutir, inclusive pra problematizar, discutir pensamentos diferentes. Isso não é comum, mas eu acho que isso faria crescer as discussões teóricas, o conhecimento (CHICO ANYSIO - E2).

O diálogo é justamente essa forma horizontal de ver que eu posso contribuir e que eu posso aprender. [...] Então, acho que essa relação como aprendente é uma relação de abertura, de olhar para o outro mesmo. Entendeu? De, além de ter o conhecimento que ele ministra, de tá aberto para que o outro pode propor e você tá aberto pra isso [...] (RACHEL DE QUEIROZ - E2).

A humildade pedagógica proposta por Jovita Feitosa pontua os fios que se alinhavam à compreensão de horizontalidade da necessidade da problematização da realidade por meio da reflexão sinalizada por Rachel de Queiroz. Na perspectiva de Rachel de Queiroz, a partir da horizontalidade do diálogo, é possível ensinar e aprender a partir dessa abertura de olhar para o outro no bojo da intersubjetividade.

A aprendizagem, por conseguinte, acontece de forma mútua, para além da hierarquia da titulação e da certificação. Entretanto, não é a negação da titulação, pois quem ensina deve dominar o ensinado. Ao contrário, é considerar que o professor sabe, mas pode aprender algo novo de alguma forma com os educandos. Em síntese, não existe saber absoluto, na mesma medida em que não existe ignorância absoluta.

Em relação aos saberes da práxis pedagógica, por conseguinte, compreende-se que as fissuras criadas pela ciência moderna - no que diz respeito às concepções sobre o processo de constituição do conhecimento, quais sejam: o reducionismo, a fragmentação, o objetivismo matematizante da realidade, o individualismo, a neutralidade científica e a disciplinaridade desarticulada do conhecimento como totalidade — podem ser superadas através da práxis pedagógica. Diametralmente em oposição a essas limitações da racionalidade técnica resultante da tessitura da ciência positiva, defende-se a recomposição da docência universitária, focalizando o professor como sujeito com saberes “entretecidos” pela subjetividade.

Os dados empíricos permitiram a afirmação na pesquisa de que a Didática é um campo de conhecimento da Pedagogia - Ciência da Educação - e tem como objeto de estudo os processos de ensinar e aprender. Ela estabelece a mediação da prática pedagógica enquanto ação situada em contexto e se preocupa com as questões sobre o que, a quem, como, porque e para ensinar.

Assim, a Didática possui generalidades que se relacionam ao processo ensino e aprendizagem, de modo geral, mas, também, evoca especificidades, pois cada área do conhecimento que constitui um campo epistemológico, por conseguinte, também constitui um campo didático, uma maneira de ensinar e de aprender própria de cada área do saber. Enfim, para além da teoria do ensino, a Didática pode ser considerada a teoria da formação permanente do professor no horizonte da práxis pedagógica. Nessa direção, destaca-se, primeiramente, que a Didática

[...] é um campo de estudo da Pedagogia que se preocupa com o ensino, que se preocupa em responder aspectos relacionados com o que ensinar, [o] porque ensinar e o como ensinar (CHICO ANYSIO - E2). 
Digo para eles que a Didática é uma disciplina e um campo de estudo, por isso estamos sempre fazendo o movimento de aprender sobre o fazer docente, ao mesmo tempo que refletimos sobre esse fazer a partir do que está sendo feito, realizado. É a reflexão da ação na ação (PAVÃO MISTERIOSO - E1).

Chico Anysio defendeu que a Didática é um campo de estudo da Pedagogia que se preocupa com o quê, o porquê e o como ensinar. Desse modo, a opção pelo currículo, a justificativa da área do conhecimento, da unidade de ensino e da aula do dia na disciplina e a metodologia que sinaliza como o professor irá transformar a ciência em matéria escolar, tornando-a compreensível aos alunos, tecem os fios da Didática em sala de aula.

Segundo Pavão Misterioso, a Didática é, ao mesmo tempo, uma disciplina e um campo de estudo. Investiga a aprendizagem da docência com base na reflexão da ação na ação. Nesse sentido, a Didática sinaliza para a prática docente a possibilidade de se tornar prática pedagógica através da reflexividade crítica sobre e na prática (SCHÕN, 1992; PIMENTA, 1996; TARDIF, 2002; THERRIEN, 2006, 2012, 2014). Diante disso, a Didática é devir que se move a partir do inacabamento, da imperfeição e da incompletude humana, no sentido da formação permanente do professor na interface entre a teoria e a prática.

A partir da proposição de Franco (2010), para quem a Didática é a teoria da formação para além da teoria do ensino, concebe-se em Freire que essa ciência pode ser considerada a teoria da formação permanente do professor no horizonte da constituição dos saberes da práxis pedagógica. Assim, a Didática proporciona ferramentas teórico-práticas para o professor pensar reflexivamente como melhorar a aula.

Nesse sentido, é possível pensar entraves e avanços da aula. Existem momentos em que a discussão avança no contexto dialógico da aula movido por perguntas. Esse processo estabelece a nutrição do debate e a (re)organização da aula, fazendo da Didática a teoria da formação permanente a partir da práxis pedagógica (FRANCO, 2010; FREIRE, 1996).

Com base nessas reflexões, faz sentido, então, trazer os dados empíricos da pesquisa para a discussão do conceito de práxis pedagógica no bojo da Didática e da formação permanente do docente universitário. Indagado sobre essas relações, um dos sujeitos freirianamente se colocou:

Sim, mas é assim mesmo, a prática é maior que a teoria, a vida é maior. Então, não vai ter nenhuma teoria que dê conta cem por cento da prática, porque a prática é maior. A dimensão da vida é maior e a prática também; porém, essa prática sem teoria fica esvaziada. E, quando ocorre a relação teoria e prática, é possível fazer um salto de qualidade que é a práxis, uma prática refletida. [...] Eu tenho a prática. Muitas vezes, o que o professor diz que é a prática, na verdade, é o ativismo que ele tem. E, muitas vezes, o professor diz: 'Ah, não preciso disso porque é a teoria, e teoria já existe demais.’ Muitas vezes, o que ele está dizendo que é teoria não é teoria, é só o [...] dizer, mas não há domínio de teoria. É por isso que, numa Pedagogia Freiriana, o importante é estabelecer essa relação entre teoria e prática; já que a prática não é dissociada de uma teoria, nem a teoria da prática, mas é necessário fazer a reflexão dessa teoria e dessa prática para construir essa práxis, que é a prática refletida (IRACEMA - E2).

Segundo Iracema, a prática é maior que a teoria, considerando que nenhuma teoria dá conta totalmente da realidade que é devir infinito. Entretanto, é preciso um cuidado com as polaridades. Aqui ela se aproximou de Freire ao destacar, de um lado, que a teoria sem prática é verbalismo inoperante (FREIRE, 1981b). Não é possível um pensamento teórico que não se traduza em ação. É infrutífero. A universidade que produz conhecimento para si mesma perdeu a sua função social.

De outro lado, a prática sem teoria é ativismo cego. Pensar uma prática que não tem embasamento teórico é outro problema a ser superado. Nota-se que toda prática pedagógica tem uma teoria que a sustenta, seja o professor consciente dela ou não. A grande questão é que ao professor é salutar que tenha consciência teórica de sua prática pedagógica, a fim de que tenha elementos para ressignificá-la. Por fim, Iracema assinalou que, em Freire, é possível pensar na práxis, de tal forma a trazer a relação entre a teoria e a prática no bojo da práxis, que é a “prática refletida” (HEERDT, 2014; FREIRE, 2001). 
Posto isso, foi questionado a Iracema, em entrevista de explicitação para aprofundar esse conceito do ponto de vista da Didática, como seria uma aula fundamentada na Pedagogia Freiriana que pudesse estabelecer relações entre a teoria e a prática. Sendo assim, ela respondeu:

Eu acho que o cerne do pensamento de Paulo Freire é justamente isso: a dialogicidade e a práxis — relação teoria e prática. Então, uma aula fundamentada na Pedagogia Freiriana que pudesse estabelecer relações entre a teoria e a prática considera o diálogo. Considera também a leitura de mundo, a leitura da realidade. É uma aula reflexiva, não é algo estanque: a teoria numa ponta e a prática em outra. Existe um diálogo entre a teoria e a prática, de modo que a prática não está dissociada da teoria nem a teoria dissociada da prática (IRACEMA - E2).

Na perspectiva de Iracema, uma aula freiriana com base na práxis pedagógica no contexto da docência universitária transita em torno da dialogicidade, da práxis, da leitura da realidade e da reflexividade. Em nossa compreensão, a dialogicidade é o fundamento pedagógico que possibilita a articulação da relação de tensão aberta entre a teoria e a prática (VOLOSKI, 2013). Assim, o diálogo estabelece caminhos para a teorização da prática, na mesma direção em que aponta situações para a prática da teoria em contexto situado, com vistas à transformação. Eis aqui a práxis pedagógica.

Para tanto, a leitura da realidade e a reflexividade (THERRIEN; CARVALHO, 2009; MARTINS; ALVIM, 2012), respectivamente, são o ponto de partida e a mola propulsora da práxis pedagógica. Assim, professores e alunos, ao lerem a realidade, ao se inserirem no contexto, podem se colocar numa condição de reflexão individual e coletiva na busca da mudança como ponto de chegada. Dessa forma, a aula se torna um espaço de constituição da utopia: ao mesmo tempo em que se denunciam os condicionantes históricos que nos impedem de Ser Mais, anuncia-se a nova realidade, o não-lugar por meio da reflexividade que permite a construção do conhecimento científico.

Esse conhecimento é que empodera os sujeitos na luta por mudanças de seu espaço social. Logo, a aula universitária é muito mais do que um lugar de blá-blá-blá teórico, mas um momento de elaboração de saberes da práxis, que transformam a realidade na mesma direção e intensidade em que transformam os sujeitos aprendentes no processo. Tal práxis pedagógica é um diálogo associativo entre teoria e prática.

\section{CONCLUSÕES}

Ao final da pesquisa, considera-se imprescindível retomar o problema e o objetivo do estudo, na busca por pensar as conclusões provisórias resultantes de um doutoramento na área de Educação. Esta investigação científica tem como problema central de pesquisa: Quais as aproximações e/ou os distanciamentos do Ciclo Gnosiológico em Paulo Freire com os saberes da docência universitária a partir de egressos do PPGE-UECE? O objetivo geral decorrente é compreender a partir da ontologia, da epistemologia e da práxis pedagógica de alunos egressos do PPGE-UECE a dialética das aproximações e/ou dos distanciamentos dos saberes da docência universitária em relação ao Ciclo Gnosiológico em Paulo Freire.

Para adentrar na empiria desse fenômeno, metodologicamente, fez-se a opção pela abordagem da pesquisa qualitativa em aproximações com a etnometodologia. Isso nos permitiu fazer opções em relação ao estudo bibliográfico, à análise documental, ao questionário on-line, aberto e semiestruturado, à entrevista com base em casos hipotéticos de ensino e à entrevista de explicitação como técnicas de coleta de dados vivenciadas com seis mestres e doutores egressos do PPGE-UECE entre 2004 (conclusão da primeira turma de mestrado) e 2017 (conclusão primeira turma de doutorado).

Nesse sentido, a análise dos dados empíricos permite defender a tese de que a tessitura do Ciclo Gnosiológico freiriano que se alinhava à do-discência e à pesquisa, materializados pela dialógica intersubjetiva, possibilita a constituição de saberes da docência universitária enviesados pelos fios ontológicos do-discentes no horizonte do Ser Mais. A racionalidade epistêmico-dialógica revela-se como referência que (re)configura a compreensão de homem, de mundo e de ciência na formação da PGSS, fazendo com que a prática docente refletida na/sobre a ação possibilite a vivência dos saberes da práxis pedagógica.

Os resultados da pesquisa apontaram que o Ciclo do Gnosiológico freiriano contribui para pensar e impulsionar a constituição dos saberes da docência universitária. No processo de formação de mestres 
e doutores na PGSS, é possível aproximar a pesquisa (aprender o que se ignora) que retroalimenta a do-discência com vistas à práxis pedagógica (ensinar o que já se sabe) com mediação do diálogo intersubjetivo enquanto dimensão pedagógica do processo de aprendizagem da docência. Tal diálogo institui e é instituinte do pensar certo, da curiosidade epistemológica, da criatividade e da criticidade na (re) constituição dos saberes da docência universitária no contexto da PGSS, no caso, especificamente, na área de Educação.

\section{REFERÊNCIAS}

BARBOSA, J. G. Multirreferencialidade nas ciências e na educação. São Carlos: EdUFSCar, 1998.

BARBOSA, S. M. C.; BARBOSA, J. G. Etnometodologia multirreferencial: contribuições teóricoepistemológicas para a formação do professor-pesquisador. Revista Educação \& Linguagem, São Paulo, ano 11, n. 18, p. 238-256, jul./dez. 2008.

BERNARDINO JÚNIOR, R. Docência universitária: o cirurgião dentista no curso de Odontologia. 2011. 236 f. Tese (Doutorado em Educação) - Universidade Federal de Uberlândia, Uberlândia, 2011.

BOUFLEUER, J. P. Pedagogia da ação comunicativa: uma leitura de Habermas. 3. ed. Ijuí: Editora Unijuí, 2001.

BRAGA, M. M. S. C. Prática pedagógica docente-discente e humanização: contribuição de Paulo Freire para a escola pública. 2012. 242f. Tese (Doutorado em Educação) - Programa de PósGraduação em Educação, Universidade Federal Pernambuco, Recife, 2012.

BRASIL. Lei n. 5.540, de 28 de novembro de 1968. Fixa normas de organização e funcionamento do ensino superior e sua articulação com a escola média, e dá outras providências. Diário Oficial da União: seção 1, Brasília, DF, p. 10369, 29 nov. 1968.

CARDARELLO, C. G. L. Pedagogia freiriana: liberdade e ensaio. 2005. 165 f. Tese (Doutorado em Educação) - Faculdade de Educação, Universidade Federal do Rio Grande do Sul, Porto Alegre, 2005.

CENTRO DE GESTÃO E ESTUDOS ESTRATÉGICOS. Mestres e doutores 2015: estudos da demografia da base técnico-científica brasileira. Brasília, DF: CGEE, 2016.

COULON, A. Etnometodologia e Educação. Tradução de Guilherme João de Freitas Teixeira. Petrópolis: Vozes, 1995.

CUNHA, C. M.; FARIAS, I. M. S.; SALES, J. A. M. A. etnometodologia: aspectos conceituais e operacionais da pesquisa. In: NUNES, J. B. C.; NÓBREGA-THERRIEN, S. M.; FARIAS, I. M. S. (org.). Pesquisa científica para iniciantes: caminhando no labirinto. Fortaleza: EdUECE, 2011. p. 123-32.

D’ÁVILA, C. M.; VEIGA, I. P. A. (org.). Didática e docência na educação superior: implicações para a formação de professores. Campinas: Papirus, 2012.

DEMO, P. Educar para a pesquisa. 5. ed. Campinas: Autores Associados, 2002.

FARIAS, I. M. S. et al. Programa Institucional de Bolsas de Iniciação a Docência no Ceará: quem são os professores supervisores? In: ENCONTRO INTER-REGIONAL NORTE, NORDESTE E CENTRO-OESTE SOBRE FORMAÇÃO DOCENTE PARA EDUCAÇÃO BÁSICA E SUPERIOR, 6., 2015, Brasília, DF. Anais [...]. Brasília, DF: [s.n.], 2015.

FARIAS, I. M. S.; BEZERRA, J. E. B. Do documento ao documento: recompondo seu lugar histórico. In: FARIAS, I. M. S.; NUNES, J. B. C. (org.). Pesquisa científica para iniciantes: caminhando no labirinto. Fortaleza: EdUECE, 2010. p. 43-53. 
FARIAS, I. M. S.; SILVA, S. P.; CAVALCANTE, M. M. S. Docentes de la educación básica activos em el pibid: ¿quiénes son?, ¿cuál su formación y experiência profesional? In: CONGRESO PEDAGOGÍA: ENCUENTRO INTERNACIONAL POR LAUNIDAD DE LOS EDUCADORES, 2015, Cuba. Anais [...]. Cuba: Palacio de Convenciones de La Habana, 2015. p. 650-660.

FELDEN, E. L. Desenvolvimento profissional docente: desafios e tensionamentos na educação superior na perspectiva dos coordenadores de área e de curso. 2013. 283 f. Tese (Doutorado em Educação) - Unidade acadêmica de pesquisa e pós-graduação, Universidade do Vale do Rio Sinos, São Leopoldo, 2013.

FERREIRA, J. C. B. Docência universitária: elementos norteadores da prática pedagógica no curso de Jornalismo. 2013. 254 f. Tese (Doutorado em Educação) - Faculdade de Educação, Universidade Federal de Uberlândia, Uberlândia, 2013.

FIGUEIREDO, J. B. A. Educação ambiental dialógica e representações sociais da água em cultura sertaneja nordestina: uma contribuição à consciência ambiental em Irauçuba/CE (Brasil). 2003. 348 f. Tese (Doutorado em Ciências Biológicas) - Centro de Ciências Biológicas e da Saúde, Universidade Federal de São Carlos, São Carlos, 2003.

FRANCO, M. A. S. Didática e Pedagogia: da teoria do ensino à teoria da formação. In: FRANCO, M. A. S.; PIMENTA, S. G. (org.). Didática: embates contemporâneos. São Paulo: Edições Loyola, 2010. p. $75-100$.

FRANCO, M. A. S. Pedagogia como ciência da educação. Campinas: Papirus, 2003.

FREIRE, P. A educação na cidade. 5. ed. São Paulo: Cortez, 2001.

FREIRE, P. Ação cultural para a liberdade. 5. ed. Rio de Janeiro: Paz e Terra, 1981b.

FREIRE, P. Extensão ou comunicação? 7. ed. Rio de Janeiro: Paz e Terra, 1983.

FREIRE, P. Pedagogia da autonomia: saberes necessários à prática educativa. 34. ed. São Paulo: Paz e Terra, 1996.

FREIRE, P. Pedagogia da indignação: cartas pedagógicas e outros escritos. São Paulo: Editora UNESP, 2000.

FREIRE, P. Pedagogia do oprimido. 9. ed. Rio de Janeiro: Paz e Terra, 1981a.

FREIRE, P. Professora sim, tia não. São Paulo: Editora Olho D’água, 1993.

FREIRE, P.; SHOR, I. Medo e ousadia: o cotidiano do professor. 7. ed. Rio de Janeiro: Paz e Terra, 1986.

GAMBOA, S. S. Saberes, conhecimentos e as pedagogias das perguntas e das respostas: atualidade de antigos conflitos. Práxis Educativa, Ponta Grossa, v. 4, n. 1, p. 9-19, jan./jun. 2009.

GARFINKEL, H. Estudios em etnometodología. México: UNAM; Bogotá: Centro de Investigaciones Interdisciplinarias en Ciencias y Humanidades, 2006.

GAUTHIER, C. et al. Por uma teoria da Pedagogia. Ijuí: Unijuí, 1998.

GEOCAPES. Sistema de dados estatísticos da CAPES. [S.l.: s.n.], 2019. Disponível em: https:// geocapes.capes.gov.br/geocapes/. Acesso em: 10 dez. 2019.

GHEDIN, E.; FRANCO, M. A. R. S. Questões de método na construção da pesquisa em educação. São Paulo: Cortez, 2011.

GIL, A. C. Como elaborar projetos de pesquisa. 4. ed. São Paulo: Atlas, 2002. 
HEERDT, B. Saberes docentes: gênero, natureza da ciência e educação científica. 2014. 240 f. Tese (Doutorado em Ensino de Ciências e Educação Matemática) - Centro de Ciências Exatas, Universidade Estadual de Londrina, Londrina, 2014.

HUBERMANN, M. Ciclo da vida profissional dos professores. In: NÓVOA, A. (org.). Vida de professores. Porto: Editora Porto, 2013. p. 31-61.

INEP. Instituto Nacional de Estudos e Pesquisas Educacionais Anísio Teixeira. Sinopse Estatística da Educação Superior - Graduação. Brasília, DF: MEC, 2017.

KINCHELOE, J. L.; BERRY, K. Pesquisa em educação: conceituando a bricolagem. Porto Alegre: Artmed, 2007.

KINCHELOE, J. L.; MCLAREN, P. Repensando a teoria crítica e a pesquisa qualitativa. In: DENZIN, N. K.; LINCOLN, Y. S. (org.). O planejamento da pesquisa qualitativa: teorias e abordagens. Porto Alegre: Artmed, 2006. p. 281-313.

LAKATOS, E. M.; MARCONI, M. A. Fundamentos de metodologia científica. 5. ed. São Paulo: Atlas, 2003.

LAPASSADE, G. A fenomenologia social e a etnometodologia. In: LAPASSADE, G. As microssociologias. Brasília, DF: Liber Livro Editora, 2005. p. 37-46. (Série Pesquisa em Educação).

LOSSO, A. R. S. Intersubjetividade. In: STRECK, D. R.; REDIN, E.; ZITKOSKI, J. J. (org.).

Dicionário Paulo Freire. 2. ed. Belo Horizonte: Autêntica Editora, 2010. p. 230-231.

MACEDO, R. S. Etnopesquisa crítica/etnopesquisa-formação. Brasília, DF: Líber Livro Editora, 2006.

MARTINS, P. A. F.; ALVIM, N. A. T. Plano de cuidados compartilhado: convergência da Proposta Educativa Problematizadora com a Teoria do Cuidado Cultural de Enfermagem. Revista Brasileira de Enfermagem, Brasília, DF, v. 65, n. 2, p. 368-73, mar./abr. 2012.

MAURENTE, V. M. M. As contribuições de um curso de formação continuada de professores que atuam nos anos iniciais acerca das concepções epistemológicas e na relação com a prática pedagógica. 2015. 135 f. Tese (Doutorado em Educação em Ciências) - Instituto de Ciências Básicas da Saúde, Universidade Federal do Rio Grande do Sul, Porto Alegre, 2015.

MENDONÇA, N. A. Pedagogia da humanização: a pedagogia humanista de Paulo Freire. São Paulo: Paulus, 2008. (Coleção Pedagogia e Educação).

NEIRA, M. G.; LIPPI, B. G. Tecendo a colcha de retalhos: a bricolagem como alternativa para a pesquisa educacional. Revista Educação e Realidade, Porto Alegre, v. 37, n. 2, p. 607-625, maio./ ago. 2012.

NUNES, R. G. Hegel, dialética, educação: sobre a contribuição da dialética hegeliana para a práxis educativa. 2002. 290 f. Tese (Doutorado em Educação) - Faculdade de Educação, Universidade Estadual de Campinas, Campinas, 2002.

OLIVEIRA, M. M. Como fazer pesquisa qualitativa. 3. ed. Petrópolis: Vozes, 2010.

OLIVEN, A. C. Histórico da educação superior no Brasil. In: SOARES, M. S. (coord.). Educação Superior no Brasil. Brasília, DF: CAPES, 2002. p. 31-42.

PIMENTA, S. G. (org.). Didática e formação de professores: percursos e perspectivas no Brasil e em Portugal. 5. ed. São Paulo: Cortez, 2008.

PIMENTA, S. G. Formação de professores: saberes da docência e identidade do professor. Revista da Faculdade de Educação, São Paulo, v. 22, n. 2, p. 72-89, jul./dez. 1996. 
PIMENTA, S. G.; ANASTASIOU, L. G. C. A. Docência no ensino superior. São Paulo: Cortez, 2002. (Coleção Docência em Formação, v. 1).

REIS, S. M. A. S. O professor do curso de odontologia e a formação odontológica atual: formação, saberes e práticas pedagógicas em tempo de novas diretrizes curriculares 2011. 311 f. Tese (Doutorado em Educação) - Universidade Federal de Uberlândia, Uberlândia, 2011.

RODRIGUES, C. S. D. et al. Pesquisa em educação e bricolagem científica: rigor, multirreferencialidade e interdisciplinaridade. Cadernos de Pesquisa, São Paulo, v. 46, n. 162, p. 966982, out./dez. 2016.

ROMÃO, J. E. Ontologia. In: STRECK, D. R.; REDIN, E; ZITKOSKI, J. J. (org.). Dicionário Paulo Freire. 2. ed. Belo Horizonte: Autêntica Editora, 2010. p. 292-294.

SANTOS, B. S. Um discurso sobre as ciências. 5. ed. São Paulo: Cortez, 2008.

SÁ-SILVA, J. R.; ALMEIDA, C. D.; GUINDANI, J. F. Pesquisa documental: pistas teóricas e metodológicas. Revista Brasileira de História e Ciências Sociais, São Leopoldo, v. 1, n. 1, p. 1-15, jul. 2009.

SAVIANI, D. Escola e democracia. Campinas: Autores Associados, 2008. (Coleção educação contemporânea).

SCHMIED-KOWARZIK, W. Pedagogia dialética: de Aristóteles a Paulo Freire. São Paulo: Editora Brasiliense, 1988.

SCHÕN, D. A. Formar professores como profissionais reflexivos. In: NÓVOA, A. (org.). Os professores e sua formação. Lisboa: Dom Quixote, 1992. p. 77-92.

SEVERINO, A. J. A pós-graduação em educação no Brasil: caminhos percorridos e horizontes a explorar. Revista educação \& linguagem, São Paulo, v. 12, n. 20, p. 273-293, jul./dez. 2009.

SILVA, M. P. Docência universitária no curso de enfermagem: formação profissional, processo de ensino-aprendizagem, saberes docentes e relações interpessoais, associados ao princípio da integralidade. 2013. 190 f. Tese (Doutorado em Educação) - Universidade Federal de Uberlândia, Uberlândia, 2013.

SILVEIRA, C. S.; ARAÚJO, S. R. P.; FARIAS, I. M. S. A etnometodologia e a busca da compreensão e interpretação dos fenômenos sociais. In: NUNES, J. B. C.; NÓBREGA-THERRIEN, S. M.; FARIAS, I. M. S. (org.). Pesquisa científica para iniciantes: caminhando no labirinto. Fortaleza: EdUECE, 2011. p. 109-121.

TARDIF, M. Saberes docentes e formação profissional. 2. ed. Petrópolis: Vozes, 2002.

THERRIEN, J. Docência profissional: a prática de uma racionalidade pedagógica em tempos de emancipação de sujeitos. In: D’ÁVILA, C. M.; VEIGA, I. P. A. Didática e docência na educação superior: implicações para a formação de professores. Campinas: Papirus, 2012. p. 109-132. (Coleção Magistério: Formação e trabalho pedagógico).

THERRIEN, J. Os saberes da racionalidade pedagógica na sociedade contemporânea. Revista Educativa, Goiânia, v. 9, n. 1, p. 67-81, jan./jun. 2006.

THERRIEN, J. Parâmetros de pesquisa científica do pesquisador de sua práxis docente - articulando didática e epistemologia da prática. In: CAVALCANTE, M. M. D. et al. (org.). Didática e a prática de ensino: diálogos sobre a escola, a formação de professores e a sociedade. Fortaleza: EdUECE, 2014. v. 4. p. 115-126. 
THERRIEN, J.; CARVALHO, A. D. O professor no trabalho: epistemologia da prática e ação/ cognição situada. Revista Brasileira de Formação de Professores, Goiânia, v. 1, n. 1, p. 129-147, maio 2009.

THERRIEN, J.; LOIOLA, F. A. Experiência e competência no ensino: pistas de reflexões sobre a natureza do saber-ensinar na perspectiva da ergonomia do trabalho docente. Educação \& Sociedade, Campinas, n. 74, p. 143-162, abr. 2001.

UECE. Centro de Educação. Coordenação de Pós-graduação e Pesquisa. Projeto do Curso de Mestrado Acadêmico em Educação. Fortaleza: UECE, 2003.

UECE. Chamada Pública 34/2016. Estabelece normas e diretrizes para o processo seletivo com vistas ao ingresso no Programa de Pós-Graduação em Educação [...]. Reitoria, Fortaleza, 2 ago. 2016.

UECE. Pró-reitoria de Pós-Graduação e Pesquisa. Centro de Educação. Proposta Institucional do Curso de Doutorado em Educação. Fortaleza: UECE, 2011.

VIEIRA, H. P. Saberes da docência universitária e Ciclo Gnosiológico em Paulo Freire: tessituras a partir da Pós-graduação em Educação. 2020. 385 f. Tese (Doutorado em Educação) - Centro de Educação, Programa de Pós-Graduação em Educação, Universidade Estadual do Ceará, Fortaleza, 2020.

VIEIRA, H. P. Saberes da docência universitária e práxis pedagógica de coordenadores de área do PIBID-UECE: um olhar a partir de Paulo Freire. 2015. 260 f. Dissertação (Mestrado em Educação) - Centro de Educação, Programa de Pós-Graduação em Educação, Universidade Estadual do Ceará, Fortaleza, 2015.

VOLOSKI, G. L. Dos lugares da filosofia da educação: reforma educacional, praticismo, formação. 2013. 163 f. Tese (Doutorado em Educação) - Centro de Ciências da Educação, Universidade Federal de Santa Catarina, Florianópolis, 2013.

WEYH, M. G. G. Práxis educativa para a formação do agricultor familiar: um estudo da prática da minhocultura em escolas rurais do município de Santo Ângelo/RS. 2008. 124 f. Dissertação (Mestrado em Educação) - Faculdade de Educação, Programa de Pós-Graduação em Educação, Universidade Federal do Rio Grande do Sul, Porto Alegre, 2008. 